\section{Targeting those left behind in Zimbabwe's HIV response: A call for decriminalisation of key populations to rapidly achieve 95-95-95 targets}

To the Editor: Zimbabwe has the sixth-highest HIV prevalence in sub-Saharan Africa, with $\sim 1.3$ million persons aged 15 - 64 years living with HIV in 2020. The country has made substantial progress towards achieving the Joint United Nations Programme on HIV/ AIDS (UNAIDS) targets of $90-90-90$ by 2020 , with $86.8 \%$ of people living with HIV diagnosed, $97 \%$ of those diagnosed on antiretroviral therapy (ART), and $90.3 \%$ of those on ART virally suppressed. ${ }^{[1]}$ This success is in line with a co-ordinated regional effort to combat the HIV epidemic. At the end of 2019, an estimated 14 African countries had achieved the $73 \%$ target, with Eswatini projected to have surpassed $86 \%$ viral suppression. ${ }^{[2]}$

In Zimbabwe, new HIV infections have declined by more than $80 \%$ since the late 1990s in a context of continuous build-up of a combination prevention response - a process that started with the scale-up of HIV prevention communications emphasising risk reduction and of condom programming. ${ }^{[3]}$ After 2010, HIV treatment access expanded rapidly. Voluntary medical male circumcision programmes were rolled out, ${ }^{[4]}$ and a national HIV programme for sex workers was scaled up. ${ }^{[5]}$ From 2010 to 2019, new HIV infections in Zimbabwe declined by $44 \% \cdot{ }^{[2]}$ Key elements of the HIV programme scale-up in Zimbabwe have included strong political commitment, a clear vision, and a strategy encompassing well-defined core packages, decentralisation of service delivery, community-based and led outreach, and continuous monitoring and quality assurance. Partnerships with civil society and community engagement have markedly strengthened national and subnational responses.

Unfocused interventions targeting the general population in Zimbabwe are unlikely to reach the 2030 95-95-95 targets, even if good retention is achieved and sustained going forward. There is therefore a need to employ targeted approaches, particularly for key populations. For instance, men who have sex with men (MSM) in Zimbabwe are at significantly increased risk of HIV infection, with a $21 \%$ prevalence, which is almost twice that of the general population. ${ }^{[6]}$ Additionally, it has been reported that the first 90 for MSM is only $34 \%$, while that of the general population is almost 2.5 times higher. Low uptake of HIV testing, prevention and treatment services among MSM has remained an important weakness of the national response. ${ }^{[7]}$ Another key population of concern is female sex workers (FSWs). A recent study reported viral load suppression $<50 \%$ among FSWs in Zimbabwe ${ }^{[8]}$ To date, innovative interventions that access networks of key populations through targeted community-based interventions have been employed in reaching these populations in the face of discriminatory laws against MSM and sex work, with varying success. ${ }^{[9,10]}$ In light of this, decriminalisation of homosexuality ${ }^{[1]}$ and sex work will improve health-seeking behaviour, including HIV services, in these two groups.

Finally, as Zimbabwe rapidly approaches the 95-95-95 targets, saturation capacity for HIV-infected individuals receiving ART in most regions underscores the need for precise geographical targeting of high-risk groups using microplanning methods ${ }^{[12]}$ to better determine the geographical loci for targeted test and start outreach activities.

\section{Godfrey Musuka}

ICAP at Columbia University, Harare, Zimbabwe

\section{Tafadzwa Dzinamarira}

Discipline of Public Health Medicine, School of Nursing and Public Health, College of Health Sciences, University of KwaZulu-Natal, Durban

anthonydzina@gmail.com

1. Population-based HIV Impact Assessment (PHIA) Project. Zimbabwe summary sheet. https://phi icap.columbia.edu/zimbabwe-2020-summary-sheet/ (accessed 5 January 2021).

2. Joint United Nations Programme on HIV and AIDS (UNAIDS). 2020 Global AIDS Update - Seizin the moment - Tackling entrenched inequalities to end epidemics. https://www.unaids.org/en/ resources/documents/2020/global-aids-report (accessed 6 April 2021)

3. Mahomva A, Greby S, Dube S, et al. HIV prevalence and trends from data in Zimbabwe, 1997 - 2004 Sex Transm Infect 2006;82(Suppl 1):i42-i47. https://doi.org/10.1136/sti.2005.019174

McGillen JB, Stover J, Klein DJ, et al. The emerging health impact of voluntary medical male circumcision in Zimbabwe: An evaluation using three epidemiological models. PLoS ONE 2018;13(7)::0199453. https://doi.org/10.1371/journal.pone.0199453

5. Cowan FM, Mtetwa S, Davey C, et al. Engagement with HIV prevention treatment and care among female sex workers in Zimbabwe: A respondent driven sampling survey. PLoS ONE 2013;8(10):e77080. https://doi.org/10.1371/journal.pone.0077080

6. Samuel K. A better understanding of African MSM's behaviour patterns will lead to optimised HIV service provision. NAM aidsmap, 13 July 2020. https://www.aidsmap.com/news/jul-2020/betterservice provision. NAM aidsmap, 13 July 2020. https://www.aidsmap.com/news/jul-2020/better-
understanding-african-msms-behaviour-patterns-will-lead-optimised-hiv-service (accessed 11 December

7. Joint United Nations Programme on HIV and AIDS (UNAIDS) and National AIDS Council an Ministry of Health and Child Care, Zimbabwe. Global AIDS Response Progress Report 2018 Zimbabwe Country Report (January 2017 - December 2017). https://www.unaids.org/sites/default files/country/documents/ZWE_2018_countryreport.pdf (accessed 11 December 2020).

8. Cowan FM, Davey C, Fearon E, et al. Targeted combination prevention to support female sex workers in Zimbabwe accessing and adhering to antiretrovirals for treatment and prevention of HIV (SAPPHIRe): A cluster-randomised trial. Lancet HIV 2018;5(8):e417-e426. https://doi.org/10.1016/s23523018(18)30111-5

9. Khumalo-Sakutukwa G, Morin SF, Fritz K, et al. Project Accept (HPTN 043): A community-based 9. Kh . Ka Thailand. J Acquir Immune Defic Syndr 2008;49(4).422-431. Ktps.//doi.org/10.1097\%2FQA1.0b013 Cornell $\mathrm{M}$

0. Cornell M, Dovel K. Reaching key adolescent populations. Curr Opin HIV AIDS 2018;13(3):274-280. htps://doi.org/10.1097/coh.000000000000045

11. Hagopian A, Rao D, Katz A, Sanford S, Barnhart S. Anti-homosexual legislation and HIV-related stigma in African nations: What has been the role of PEPFAR? Glob Health Action 2017;10(1):1306391 https://doi.org/10.1080/16549716.2017.130639

12. Cuadros DF, Li J, Mukandavire Z, et al. Towards UNAIDS Fast-Track goals: Targeting priority geographic areas for HIV prevention and care in Zimbabwe. AIDS 2019;33(2):305-314. https://doi. org/10.1097/qad.0000000000002052

S Afr Med J 2021;111(5):385. https://doi.org/10.7196/SAMJ.2021.v111i5.15567 